\title{
Factors Constraining Timely Sowing of Wheat as an Adaptation to Climate Change in Eastern India ${ }^{\circ}$
}

\author{
DANiElle NewPort, ${ }^{\mathrm{a}}$ DAVID B. Lobell, ${ }^{\mathrm{b}}$ BAlwinder-Singh, ${ }^{\mathrm{c}}$ AMIT K. SRIVASTAVA, ${ }^{\mathrm{c}}$ \\ PREETI RAO, ${ }^{\mathrm{a}}$ MAANYA UMASHAANKER, ${ }^{\mathrm{a}}$ RAM K. MALIK, ${ }^{\mathrm{c}}$ ANDREW MCDONALD, ${ }^{\mathrm{d}}$ \\ AND MEHA JAIN ${ }^{\mathrm{a}}$ \\ ${ }^{a}$ School for Environment and Sustainability, University of Michigan, Ann Arbor, Michigan \\ ${ }^{b}$ Department of Earth System Science and Center on Food Security and the Environment, Stanford \\ University, Stanford, California \\ ${ }^{c}$ International Maize and Wheat Improvement Center (CIMMYT), New Delhi, India \\ ${ }^{d}$ Soil and Crop Sciences Section, School of Integrative Plant Science, Cornell University, \\ Ithaca, New York
}

(Manuscript received 20 September 2019, in final form 26 February 2020)

\begin{abstract}
Climate change is predicted to negatively impact wheat yields across northern India, primarily as a result of increased heat stress during grain filling at the end of the growing season. One way that farmers may adapt is by sowing their wheat earlier to avoid this terminal heat stress. However, many farmers in the eastern Indo-Gangetic Plains (IGP) sow their wheat later than is optimal, likely leading to yield reductions. There is limited documentation of why farmers sow their wheat late and the potential constraints to early sowing. Our study uses data from 256 farmers in Arrah, Bihar, a region in the eastern IGP with late wheat sowing, to identify the socioeconomic, biophysical, perceptional, and management factors influencing wheat-sowingdate decisions. Despite widespread awareness of climate change, we found that farmers did not adopt strategies to adapt to warming temperatures and that wheat-sowing dates were not influenced by perceptions of climate change. Instead, we found that the most important factors influencing wheat-sowing-date decisions were irrigation type and cropping decisions during the monsoon season prior to the winter wheat growing season. Specifically, we found that using canal irrigation instead of groundwater irrigation, planting rice in the monsoon season, transplanting rice, and transplanting rice later during the monsoon season were all associated with delayed wheat sowing. These results suggest that there are system constraints to sowing wheat on time, and these factors must be addressed if farmers are to adapt wheat-sowing-date decisions in the face of warming temperatures.
\end{abstract}

\section{Introduction}

The rice-wheat system in India's Indo-Gangetic Plains (IGP) is one of the most important agricultural systems in the world, and India is the second largest producer of both rice and wheat globally (Singh 2018). This region is expected to face some of the largest negative impacts on crop yields due to warming temperatures associated with climate change (Kumar et al. 2014). This is particularly true for wheat, where terminal heat stress during

Supplemental information related to this paper is available at the Journals Online website: https://doi.org/10.1175/WCAS-D-190122.s1.

Corresponding author: Meha Jain, mehajain@umich.edu grain filling currently reduces yields by $5 \%$ and is expected to further negatively impact yields over the coming decades (Lobell et al. 2011; Kumar et al. 2014). As India's population continues to grow, these losses pose a serious threat to food security. One way to reduce the negative impacts of warming temperatures is to sow wheat on time, by 15 November across the IGP, which allows for the crop to mature prior to heat stress at the end of the growing season (Kalra et al. 2008; Pathak et al. 2015). The implementation of practices promoting on-time sowing are crucial because even with the development of new agricultural technologies, late sowing remains one of the key factors impacting wheat yields across the IGP (Tripathi et al. 2005; Reynolds et al. 2008; Hobbs et al. 2019).

In the western IGP, in the states of Punjab, Haryana, and western Uttar Pradesh, farmers already sow wheat 
close to the ideal date of 15 November (Vyas et al. 2013; Chakraborty et al. 2018). In the eastern IGP, in the states of eastern Uttar Pradesh and Bihar, wheat is sown much later than the west (Vyas et al. 2013; Chakraborty et al. 2018), sometimes as late as early January (Jain et al. 2016). Studies have shown that sowing wheat just one week earlier than current planting dates is associated with yield gains of approximately $5 \%$ in the western IGP (Lobell et al. 2013). It is likely that yield gains from early planting would be even greater in the east given that yield decline from late planting is $1.5-2.0$ times that in the west, primarily due to a shorter winter window for growth of wheat in the east (Chandna et al. 2004). Despite the long established benefits of sowing wheat by 15 November (Ortiz-Monasterio et al. 1994), a large proportion of farmers across the IGP, particularly the eastern IGP, sow their wheat late (Chakraborty et al. 2018).

There is little understanding of why a large proportion of farmers in the eastern IGP sow wheat later than is recommended. Previous studies, primarily conducted in the western IGP, have suggested that wheat sowing is delayed due to late rice establishment, the prevalence of planting long-duration rice, and the long turnover period for fields between rice harvest and wheat sowing (Ladha et al. 2003; Rao et al. 2015). For example, Balwinder-Singh et al. (2015) found that delaying rice establishment (and in turn rice harvesting) in the western IGP results in later sowing of wheat. Farmers may be able to overcome these challenges by adopting alternate sowing and field preparation practices. Considering earlier rice establishment, studies in Malaysia and the Philippines have shown that direct seeding of rice seeds into dry soil in place of transplanting rice seedlings into puddled fields reduces land preparation time and leads to earlier establishment of rice crops, as farmers did not have to wait for fields to become saturated with irrigation or rainfall before sowing (Cabangon et al. 2002; Tuong et al. 2000; Lantican et al. 1999). In addition, farmers may be able to reduce the turn over period length between rice and wheat by using zero till, which does not require farmers to till the soil prior to sowing wheat, reducing land preparation time and allowing for earlier wheat planting (Rafiq et al. 2017; Hobbs 2001).

To date, there is limited documentation of the proportion of farmers who sow wheat later than 15 November, which factors are associated with late wheat sowing, and whether farmers are adopting any technologies, such as direct seeding or zero till, to help sow wheat earlier in the eastern IGP. Yet understanding these issues is important as it helps identify which factors are the largest constraints to sowing wheat earlier and may be the most effective leverage points for interventions to encourage earlier sowing in the face of climate change. We focus our study on one region that faces late sowing dates, Arrah, Bihar, located in the eastern IGP. We examine the socioeconomic, biophysical, perceptional, and management factors that are associated with both wheatsowing date and rice-planting decisions, as monsoon crop decisions can impact wheat-sowing date. We specifically seek to answer the following questions:

1) Which socioeconomic, biophysical, perceptional, and management factors are associated with late wheatsowing dates?

2) Do monsoon cropping decisions affect the sowing date of wheat in the winter growing season? If so, which factors are driving monsoon cropping decisions?

3) What are farmers' perceptions of climate change, and do these perceptions influence rice- and wheatcropping decisions?

In this study, we aim to identify the factors influencing the timing of the rice-wheat-cropping system. Such information could help policy makers target interventions and policies to help farmers sow wheat earlier, reducing a large proportion of the negative impacts of warming temperatures caused by climate change, and ensuring that wheat yields continue to meet rising food demand in this important agricultural region.

\section{Study region and methods}

\section{a. Study region}

Located in the eastern Indian state of Bihar, our study is based in the district of Arrah, where approximately $50 \%$ of the population lives on rural agricultural lands (Directorate of Census Operations, Bihar 2011). The fertile plains that make up this district make it suitable for its predominantly agricultural economy, whose main agricultural crops and commercial exports are rice and wheat (Ministry of Micro, Small and Medium Enterprises 2011). We selected a $16 \mathrm{~km} \times 8 \mathrm{~km}$ region in Arrah (Fig. 1) that we knew had variation in wheatsowing times based on previous fieldwork and satellite image analysis of sowing dates across the region (Jain et al. 2016; Fig. S1 in the online supplemental material); our study area is also located in one of the regions with the greatest amount of late wheat sowing across the eastern IGP (Fig. S1). Furthermore, this region is facing terminal heat stress (Fig. S2A in the online supplemental material), which is associated with reduced wheat yields with later sowing dates (Fig. S2B).

\section{b. Data collection and descriptive statistics}

To design the structured household survey, we first conducted one focus group in each village we visited 


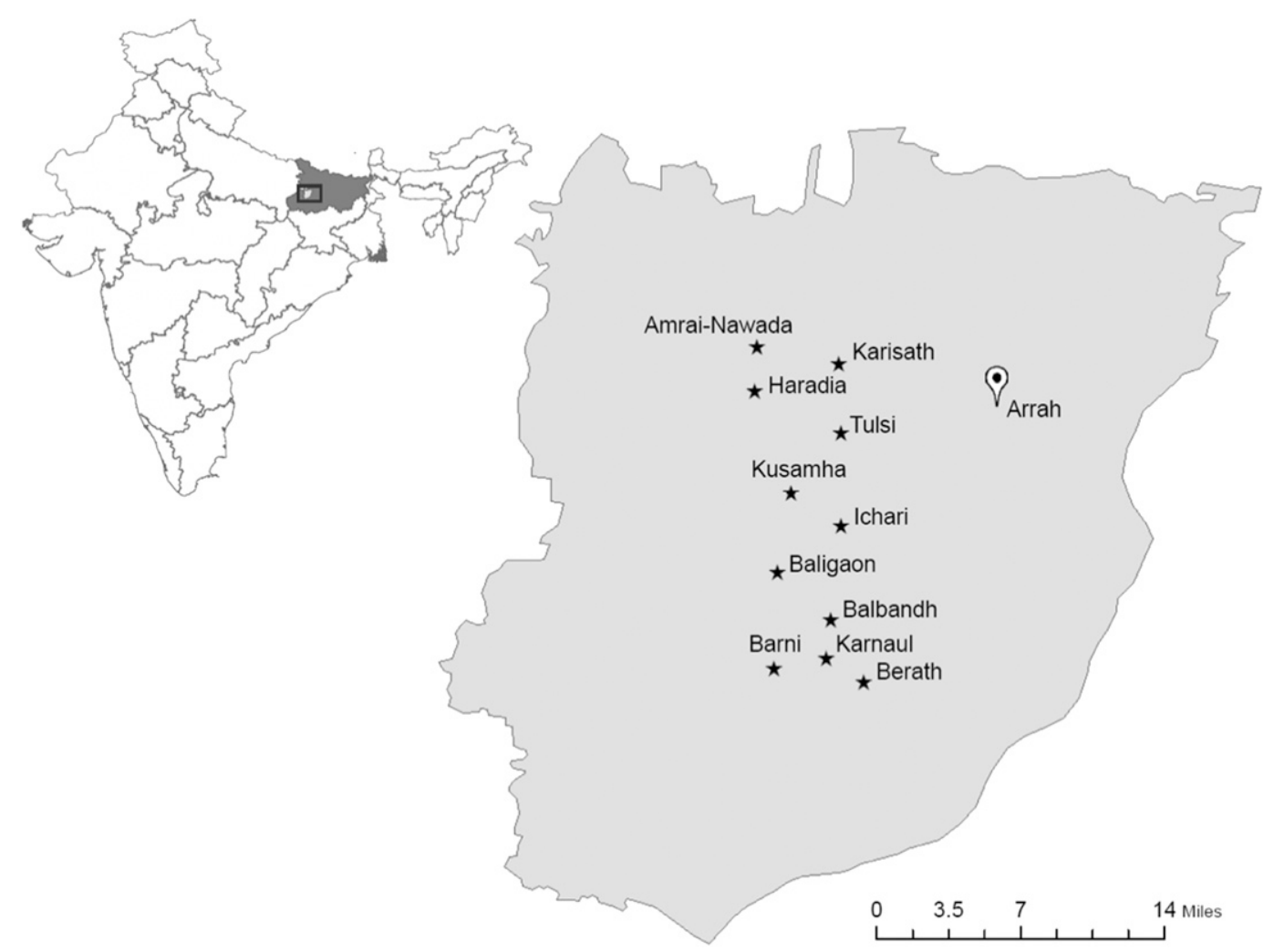

FIG. 1. Map of villages considered in this study. The district of Arrah within the state of Bihar is highlighted in light gray within the outline in the inset. Villages (marked by stars) are west of the city of Arrah (marked by pin).

with farmers to identify potential factors that may influence wheat-sowing-date decisions and potential constraints to sowing early. These focus groups helped inform what questions we ultimately included in our structured household survey and also the set of potential responses that were coded for each question. All questions were open ended, and our field team selected the coded response that matched each farmer's open-ended response. We also included "other" as a potential response category that allowed for our survey team to write in a farmer's response if it was different from the structured coded responses for each question (please see the online supplemental information for a copy of the survey). We then translated this survey into Hindi, which is spoken by all farmers in our study region. After we designed the structured household survey, field staff conducted mock interviews with farmers to ensure that our survey questions were worded appropriately, that the translation was correct, and that our coded list of answers to each question included the most common responses given by farmers.

Once the survey was finalized, we selected 11 villages that were distributed across the study region, represented the range in wheat-sowing dates across the region, and were independent of the locations where we conducted focus groups and survey training (Fig. 1). Within each village, we interviewed approximately 25 farmers. These farmers were selected using a stratified sampling design, where we stratified farmer selection across landholding size and caste. Landholding size and caste have been shown to be proxies for socioeconomic status and crop-management decisions in India (Jain et al. 2015), and if we apply stratified sampling across these categories, we likely would observe the full range of crop-management decisions within a village. We first spoke with government officials from the village Panchayat, or local government, to obtain an estimate of the distribution of farmers across landholding sizes and castes within the given village. We then visited households for our survey throughout the village, ensuring that the distribution of landholding size within our survey sample matched our village distributions. The households that we selected were also geographically distributed throughout the village to ensure that we sampled farmers from each of the different neighborhoods across each village since castes are typically clustered in neighborhoods within a village.

Within each household, we asked to speak to the main household member in charge of agricultural decisionmaking (over $99 \%$ of our respondents were the male 
TABLE 1. Summary statistics for all variables included in regressions.

\begin{tabular}{|c|c|}
\hline Wheat sow date $(N=254)$ & Mean $=3$ Dec $;$ median $=30$ Nov $;$ range $=1$ Nov -18 Jan \\
\hline Irrigation type $(N=248)$ & $\begin{array}{l}100 \% \text { of farmers have irrigation; } 5.4 \% \text { are canal irrigated, } 65.6 \% \text { rent water from another } \\
\text { farmer's bore well, and } 29 \% \text { use water from their own bore well }\end{array}$ \\
\hline Max education level $(N=255)$ & $\begin{array}{l}\text { 8.47\% had no schooling, } 38.71 \% \text { went to primary school, } 26.21 \% \text { graduated from the } 10 \text { th } \\
\text { standard, } 12.5 \% \text { graduated from the } 12 \text { th standard, } 0.4 \% \text { received a diploma, and } 13.71 \% \\
\text { earned a B.A./B.Sc. }\end{array}$ \\
\hline Risk $(N=249)$ & $\begin{array}{l}\text { Category } 1=36.78 \% \text {, category } 2=16.12 \% \text {, category } 3=11.57 \% \text {, and category } 4=35.54 \% \text {, } \\
\text { where category } 1 \text { represents the least risky answer and category } 4 \text { represents the most } \\
\text { risky answer to a question that asked farmers how much money they would bet on getting } \\
\text { heads in a coin-flipping game }\end{array}$ \\
\hline Tilling practices $(N=245)$ & $\begin{array}{l}96 \% \text { of farmers till their soils with tractors, } 1 \% \text { till their fields using ox plots, and } 2.4 \% \text { use } \\
\text { zero-tillage technologies }\end{array}$ \\
\hline Age $(N=253)$ & Mean $=51 ;$ median $=50 ;$ range $=22-83$ \\
\hline Wealth index $(N=256)$ & $\begin{array}{l}\text { Mean }=5.76 ; \text { median }=5 ; \text { range }=0-22[\text { sum of all durable goods (bikes, television, etc.) } \\
\text { that a landowner owns] }\end{array}$ \\
\hline Soil type $(N=256)$ & $\begin{array}{l}45.4 \% \text { of farmers had dark clay soil, } 24.10 \% \text { had sandy loam soil, and } 30.5 \% \text { had other } \\
\text { soil types }\end{array}$ \\
\hline Topography $(N=240)$ & $\begin{array}{l}31.20 \% \text { have lowland topography, } 5.56 \% \text { have midland topography, and } 63.25 \% \text { have } \\
\text { upland topography }\end{array}$ \\
\hline & $6.83 \%$ yes; $23.17 \%$ no \\
\hline
\end{tabular}

Has the winter growing-season temperature changed relative to 10 years ago? $(N=253)$

Monsoon crop $(N=229)$

Rice variety duration $(N=203)$

Sowing method $(N=201)$

Rice transplant date $(N=197)$
$66 \%$ warmed; $15 \%$ cooler; $10 \%$ more variable; $9 \%$ no change

$89.19 \%$ of farmers plant rice; $10.81 \%$ leave land fallow during monsoon season Mean $=112$ days; median $=115$; range $=60-165$ days

$95.92 \%$ of farmers transplant their rice; $4.08 \%$ use direct seeding to plant rice

Mean $=29 \mathrm{Jul}$; median $=28 \mathrm{Jul}$; range $=3 \mathrm{Jun}-28$ Aug head of the household) and asked if this person would be willing to take part in our 45-min household survey. Consent was obtained following an approved institutional review board (IRB) protocol (eProtocol 30648; Stanford University) and farmers were told that they could stop taking the survey at any time. We ensured that no other farmers from the village were present in the house at the time of survey collection so that responses were not biased by other farmers. If a farmer's response to each question was one of the a priori coded responses, our survey team would select the associated response. However, if a farmer gave a different answer that was not one of the available response choices, our survey team selected "other" and wrote out the farmer's response. These free-form answers were later coded if there was more than one of the same response across all of our surveys.

We described each of the variables considered in our analyses and produced descriptive statistics (Table 1). All farmers in our sample had access to irrigation, and the reported irrigation sources were canal $(5 \%)$, own bore well $(29 \%)$, and others' bore well $(66 \%)$. When using canal irrigation, farmers draw water using diesel pumps from nearby canals, and when using bore well irrigation, farmers draw groundwater using diesel pumps from wells dug near their fields. Own bore well refers to farmers who own their own well, and others' bore well refers to farmers who do not own their own bore well, but instead purchase water from bore well owners in their village at an hourly rate. Most farmers planted rice during the monsoon season $(89 \%)$, though some farmers left their monsoon land fallow $(11 \%)$. Of those farmers who planted rice, $96 \%$ of farmers transplanted their rice and $4 \%$ used direct seeding of rice. The soil types of farmers' fields were either of dark clay (45\%), sandy loam $(24 \%)$, or other $(31 \%)$, a category that represented soils other than the two aforementioned soil types. The median size of farmers' plots was 2.5 acres. The highest level of education completed by most farmers was primary school $(39 \%)$, followed by the 10 th grade $(26 \%)$.

\section{c. Statistical analyses}

So as to not overrepresent farmers with multiple plots of land, regressions were run using data from each farmer's largest field. To ensure that selecting only farmers' largest fields did not bias our results, we compared the mean and variance of wheat-sowing dates for the largest fields with those of all fields (Fig. S3 in the online supplemental material) and found that they were not significantly different $(p>0.05)$. For regressions on continuous variables (e.g., sowing date, 
TABLE 2. Effect, in terms of number of days $( \pm)$ relative to the reference, of various socioeconomic, biophysical, perceptional, and management factors on the wheat-sowing-date dependent variable, with the full dataset (regression 1: all data), for only farmers growing rice (regression 2: rice subset), and for only farmers who transplanted their rice (regression 3: transplant subset). Reference levels were canal for irrigation, ox plow for tilling, dark clay for soil type, lowland for topography, and fallow for monsoon crop type. Significance is indicated with the following symbols: plus sign for $p<0.1$, asterisk for $p<0.05$, two asterisks for $p<0.01$, and three asterisks for $p<0.001$. Here, df is degrees of freedom, and the other numbers in parentheses are standard errors.

\begin{tabular}{|c|c|c|c|}
\hline & All data & Rice subset & Transplant subset \\
\hline Others' bore well & $-13.761^{\text {*** }}(4.774)$ & $-14.215^{* *}(5.061)$ & $-13.615^{*}(5.357)$ \\
\hline Own bore well & $-8.892^{+}(5.051)$ & $-10.515^{+}(5.347)$ & $-9.503^{+}(5.544)$ \\
\hline Tractor tilling & $-7.989(9.788)$ & $-5.682(10.234)$ & $-5.531(10.255)$ \\
\hline Zero tillage & $1.966(12.392)$ & $3.528(12.848)$ & $-2.188(14.037)$ \\
\hline Education & $0.434(0.784)$ & $0.742(0.877)$ & $0.877(0.877)$ \\
\hline Risk & $0.275(0.906)$ & $0.280(0.997)$ & $0.287(1.016)$ \\
\hline Age & $-0.069(0.074)$ & $-0.071(0.084)$ & $-0.025(0.084)$ \\
\hline Wealth & $-0.346(0.390)$ & $-0.124(0.432)$ & $-0.082(0.435)$ \\
\hline Other soil & $2.321(2.550)$ & $1.220(2.821)$ & $2.058(2.916)$ \\
\hline Sandy loam soil & $-1.445(2.679)$ & $-0.066(2.940)$ & $0.073(2.927)$ \\
\hline Midland topography & $0.538(4.313)$ & $-3.746(5.029)$ & $-1.917(4.995)$ \\
\hline Upland topography & $2.069(2.269)$ & $0.436(2.501)$ & $0.383(2.506)$ \\
\hline Warm temperature impacts yields & $3.962(2.545)$ & $2.894(2.832)$ & $4.208(2.824)$ \\
\hline Growing-season temperature has changed & $-0.410(3.668)$ & $0.772(4.321)$ & $0.697(4.315)$ \\
\hline Plant rice & $7.213^{*}(3.382)$ & & \\
\hline Rice duration & & $0.065(0.071)$ & $0.059(0.071)$ \\
\hline Transplant rice & & $9.820^{+}(5.797)$ & \\
\hline Transplant date & & & $0.180^{*}(0.090)$ \\
\hline Constant & $45.148^{* * *}(14.418)$ & $33.291^{+}(18.163)$ & $27.767(18.842)$ \\
\hline No. obs & 174 & 154 & 149 \\
\hline$R^{2}$ & 0.166 & 0.158 & 0.157 \\
\hline Adjusted $R^{2}$ & 0.087 & 0.060 & 0.054 \\
\hline Residual std error & $13.233(\mathrm{df}=158)$ & $13.852(\mathrm{df}=137)$ & $13.540(\mathrm{df}=132)$ \\
\hline$F$ statistic & $2.102 *(\mathrm{df}=15 ; 158)$ & $1.608^{+}(\mathrm{df}=16 ; 137)$ & $1.533^{+}(\mathrm{df}=16 ; 132)$ \\
\hline
\end{tabular}

duration), we used linear regressions to identify the factors influencing the dependent variable in question. We ensured that all of our continuous covariates had linear relationships with our dependent variable of interest (Fig. S4 in the online supplemental material). For regressions on binomial categorical variables (e.g., crop type), we ran binomial logistic regressions to find the factors increasing likelihood of choosing one category over the other. R Project software and the relaimpo, $\mathrm{glm}$, and stargazer packages were used for data analysis and visualization.

We specifically ran three regressions using wheatsowing date as the dependent variable including 1) all farmers, 2) a subset of farmers that grew rice in the monsoon season, and 3) a subset of farmers that transplanted rice. It is important to note that the sample size for each regression is less than 256 (the total number of farmers we interviewed) because some farmers did not provide information for all variables that were considered in our regression (see Table 1 for number of responses for each variable). We tested whether the subset of data used in the regression was representative of the full dataset by comparing the mean and variance of wheat-sowing date between the subset of data $(n=174)$ and the full dataset $(n=256)$ and found no significant differences $(p>0.05)$. Since cropping decisions in the monsoon season influence wheat-sowing dates, we also ran three regressions with monsoon cropping decisions as the dependent variables: 1) whether the farmer planted rice, 2) the transplant date of rice, and 3) the duration of rice. Beta coefficients and significance levels are presented for all of the independent variables in each regression to determine which factors significantly influence our dependent variables of interest (Tables 2 and 3$)$.

\section{d. Scenario analysis}

To gain a better understanding of the possible benefits of adopting different crop-management strategies, we used the results of our linear regression models to estimate the overall change in wheat-sowing dates that could occur if farmers adopted different management practices. We specifically did this by replacing the suboptimal management strategy in our dataset with the optimal management strategy, and then applied the beta coefficients from our linear model to this amended 
TABLE 3. Effect, in terms of number of days ( \pm ) relative to the reference, of socioeconomic, biophysical, perceptional, and management factors on the dependent variables monsoon crop choice [regression 1: plant rice (logistic)], rice transplant date [regression 2 (OLS)], and rice duration [regression 3: (OLS)]. Reference levels were canal for irrigation, dark clay for soil type, and lowland for topography. Significance is indicated with the following symbols: plus sign for $p<0.1$, a single asterisk for $p<0.05$, two asterisks for $p<0.01$, and three asterisks for $p<0.001$. Here, $\mathrm{df}$ is degrees of freedom, and the other numbers in parentheses are standard errors.

\begin{tabular}{lccc}
\hline \hline & Plant rice & Rice transplant date & Rice duration \\
\hline Others' bore well & $-16.276(1696.799)$ & $3.736(4.302)$ & $-11.907^{*}(5.740)$ \\
Own bore well & $-15.374(1696.799)$ & $0.913(4.519)$ & $-6.796(6.019)$ \\
Education & $-0.008(0.199)$ & $0.104(0.771)$ & $2.058^{*}(0.994)$ \\
Risk & $0.524^{*}(0.241)$ & $1.477^{+}(0.861)$ & $-0.350(1.144)$ \\
Age & $0.021(0.020)$ & $-0.067(0.076)$ & $-0.027(0.099)$ \\
Wealth & $-0.085(0.094)$ & $-0.186(0.384)$ & $-0.560(0.477)$ \\
Other soil & $-2.450^{* *}(0.822)$ & $-4.544^{+}(2.411)$ & $9.817^{* * *}(3.217)$ \\
Sandy loam soil & $-2.195^{* *}(0.799)$ & $-2.007(2.655)$ & $-2.187(3.481)$ \\
Midland topography & $-2.328^{*}(1.036)$ & $-5.382(4.494)$ & $11.124^{+}(5.981)$ \\
Upland topography & $-0.569(0.629)$ & $1.189(2.228)$ & $2.867(2.919)$ \\
Transplant rice & & & $0.885(7.477)$ \\
Transplant date & & & $0.083(0.106)$ \\
Constant & $18.682(1696.799)$ & $56.409^{* * *}(6.894)$ & $110.332^{* * * *}(11.756)$ \\
No. obs & 189 & 157 & 163 \\
$R^{2}$ & & 0.072 & 0.174 \\
Adjusted $R^{2}$ & & 0.009 & 0.107 \\
Log likelihood & -52.948 & & $16.687(\mathrm{df}=150)$ \\
Akaike information criterion & 127.895 & $1.137(\mathrm{df}=10 ; 146)$ & $2.625^{* *}(\mathrm{df}=12 ; 150)$ \\
Residual std error & & & $12.502(\mathrm{df}=146)$ \\
$F$ statistic & & &
\end{tabular}

dataset to predict sowing dates. To develop a viable comparison dataset of current sowing dates, we predicted wheat-sowing dates using the original dataset. We used these simulated sowing dates as our baseline scenario instead of observed sowing dates since the linear model has error and is not able to predict the observed sowing dates exactly. For the scenarios that only considered a subset of farmers in our models (e.g., scenarios that only considered rice farmers), we included the baseline predicted sowing dates for farmers who were not included in the subset so that we had sowing dates for all farmers in all scenarios. It is important to note that we are not trying to simulate farmers' abilities to adapt to future climate change with these scenarios; we only want to understand how much changing management strategies may enhance earlier wheat sowing.

\section{Results}

\section{a. Perceptions of ideal wheat-sowing date, constraints to wheat yields, and climate change}

The average wheat-sowing date for the farmers in our sample for the year in which we conducted the study was 2 December, which is two weeks later than the optimal sowing date of 15 November, suggested by agronomists for the eastern IGP region (Ortiz-Monasterio et al. 1994; Department of Agriculture 2019). When asked what they perceived to be the ideal wheat-sowing date, $70.7 \%$ of farmers responded that $16-30$ November is the range in which they would ideally sow wheat (Fig. 2a). However, only $41.5 \%$ of farmers actually sowed wheat within this window (Fig. 2b). Compared to the $8 \%$ reporting dates after 30 November as their ideal planting window, $47 \%$ of farmers actually sowed wheat after 30 November.

The majority of farmers responded that they did not plant wheat within their ideal sowing window because their rice crop was still standing (Fig. 2c). It is common for farmers in this region to plant rice during the monsoon season, with $89 \%$ growing rice and $11 \%$ leaving fields fallow. The average establishment date for rice is 29 July, and the average duration that rice is in a farmer's field is 112 days, which does not account for the amount of time seedlings were grown in nurseries. Additionally, farmers reported lack of inputs such as irrigation and fertilizer to be their biggest constraints to increasing wheat yield, whereas late sowing and high temperature were rarely listed as constraints (Fig. 2d).

It is clear that farmers realize there are benefits to sowing earlier; in fact, $77 \%$ of the farmers in this region responded that they were aware that high temperatures in March reduce wheat yields (Table 1). In addition, $66 \%$ of farmers also reported that the growing-season temperatures had warmed over the last 10 years (Table 1). Despite their perceptions of the negative 
Ideal Wheat Sow Date

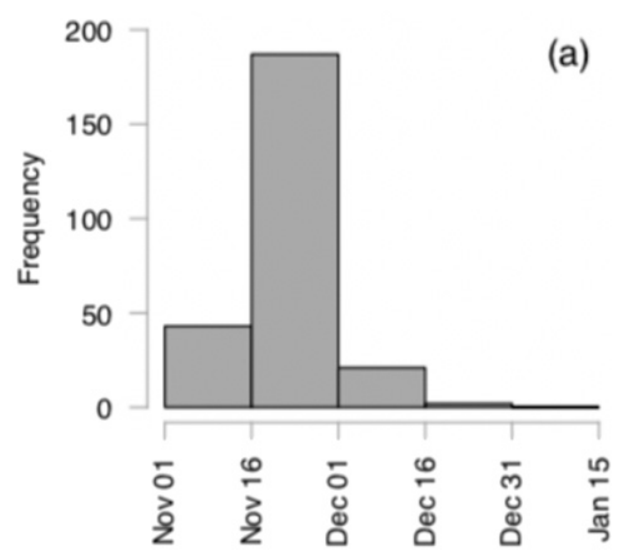

\section{Reason for not planting in ideal sowing window}

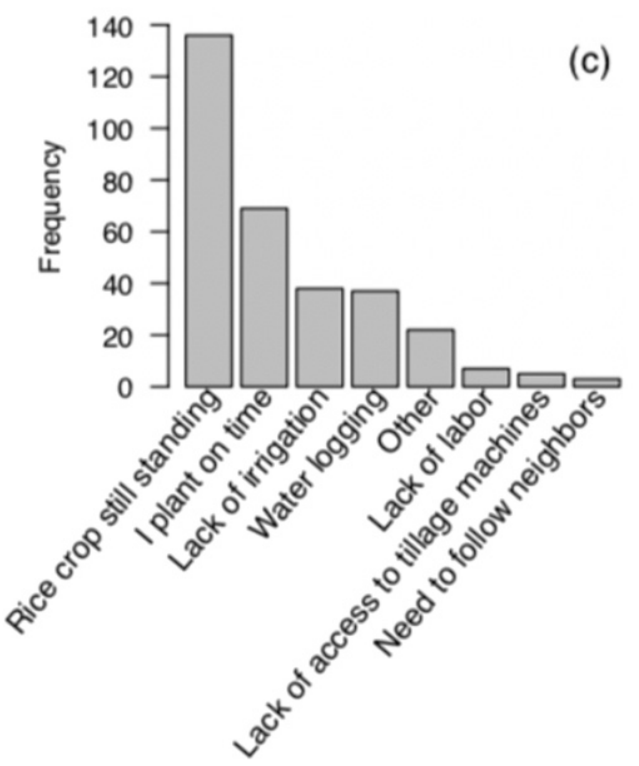

Actual Wheat Sow Date

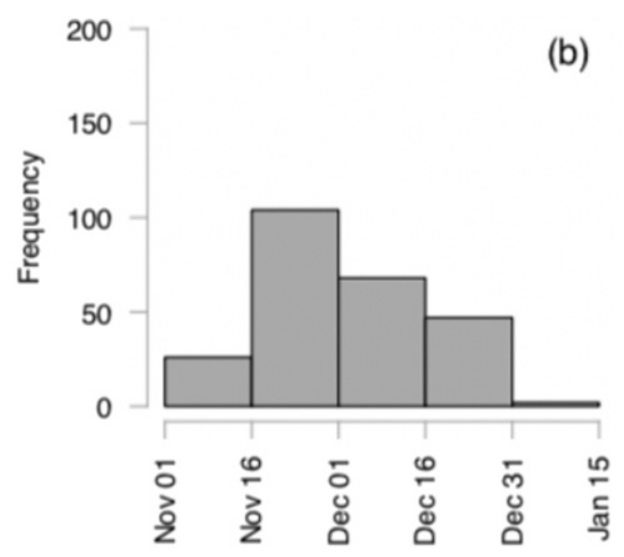

Constraints to Increasing Yield

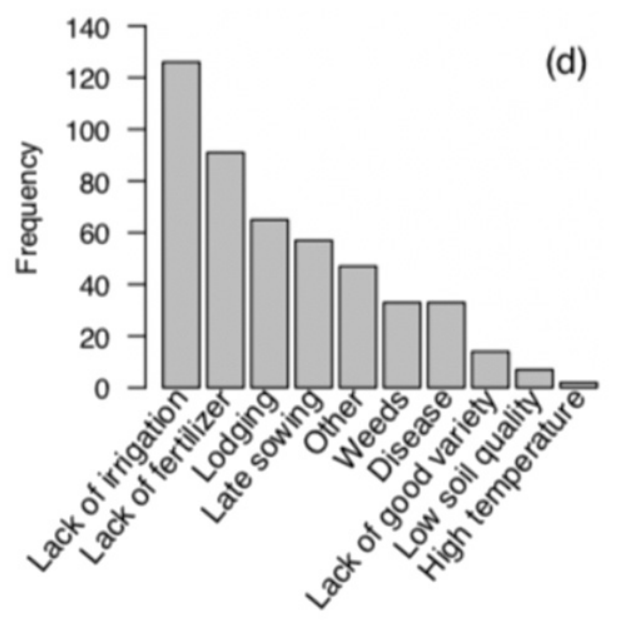

FIG. 2. Farmers' (a) ideal sowing date, (b) actual sowing date, (c) reason for not planting within their ideal sowing window, and (d) constraints to increasing yield.

effects of warm temperatures in March and rising growingseason temperatures, all farmers responded that they have not made any adaptations to mitigate the effects of warming temperatures, with most farmers saying that they either did not know what to do or that there was nothing they could do to reduce the negative impacts of warming temperatures.

We also asked questions about zero-till adoption and found that $96 \%$ of farmers had heard of zero till (Fig. S5a in the online supplemental material), yet only $2.5 \%$ of farmers reported using zero till in their largest wheat field during the growing season for which we collected data (Fig. S5b). Instead of using zero till, the most common land preparation method stated was using tractors for tilling (96\% of farmers; Fig. S5b). When considering the use of zero till, it is important to understand how rice residues are cleared from the field prior to wheat land preparation. In this region, approximately $60 \%$ of fields are mechanically harvested, leaving behind large rice residues that are difficult to dispose of quickly, resulting in most farmers burning their residue. Approximately $40 \%$ of farmers hand harvest their 
fields and these farmers remove rice residues manually, with small, anchored residues remaining in the field.

\section{b. Factors affecting wheat-sowing dates}

When considering all farmers, one of the variables we found to affect wheat-sowing date is irrigation source (Table 2; regression 1). When compared with those who used canal irrigation, farmers using their own bore water sowed wheat 9 days earlier $(p<0.1)$ and farmers using others' bore water sowed wheat 14 days earlier $(p<$ $0.01)$. Farmers who planted rice instead of leaving their land fallow during the monsoon season sowed wheat 7 days later $(p<0.05)$. This finding corroborates responses from farmers who said that the standing rice crop was their biggest obstacle to sowing wheat on time (Fig. 2c).

Since planting rice was one of the factors that was most associated with delayed wheat sowing, we ran a regression for only those farmers who grew rice to identify if there were any rice-management factors associated with late wheat sowing (Table 2; regression $2)$. We find that having access to bore well irrigation was again associated with earlier sowing of wheat; specifically, compared to canal irrigation, farmers sowed wheat 14 days earlier if they irrigated from others' bores $(p<0.01)$ and 11 days earlier if they used their own bore water $(p<0.1)$. In addition, we find that direct seeding of rice instead of transplanting rice is associated with earlier wheat sowing by 10 days $(p<0.1)$. We then investigated which factors were associated with wheatsowing date for farmers who transplanted rice during the monsoon season (Table 2; regression 3). We again found that irrigation source affects these farmers' wheat-sowing date. When compared with those who used canal irrigation, farmers using their own bore water sowed wheat 10 days earlier $(p<0.1)$ and farmers using others' bore water sowed wheat 14 days earlier $(p<0.05)$. We found that for each day later that farmers transplanted their rice, the wheat-sowing date was 0.2 days later $(p<0.05)$.

\section{c. Monsoon-season decisions}

When we examined what factors are associated with whether a farmer decided to plant rice or leave fields fallow, we found that risk, soil type, and topography were significantly associated with crop choice (Table 3; regression 1). Farmers with sandy loam soil and other soils were more likely to leave fields fallow than those farmers with sandy clay soil $(p<0.01)$. This is expected given that sandy clay soil is able to retain water better than other soil types, making it well suited to planting rice. In addition, farmers who were identified as more risk taking were more likely to plant rice $(p<0.05)$.
We then examined which factors explained rice transplant date for those farmers who grew rice and transplanted seedlings into their fields ( $>96 \%$ of farmers) (Table 3; regression 2). We found that increased risktaking attitudes were positively associated with later rice transplant dates $(p<0.1)$. Additionally, other soil type was associated with earlier transplanting than farmers with sandy loam and dark clay soils $(p<0.1)$.

Although rice duration was not a significant predictor in our regression of wheat-sowing date for farmers planting rice during the monsoon season, we wanted to understand the factors influencing farmers' choice in rice varieties since rice crops still standing in field was the main constraint for sowing wheat on time (Table 3; regression 3). We found that farmers whose fields were made up of other soil types were more likely to sow longer-duration rice varieties than farmers with sandy loam and dark clay soils $(p<0.01)$. In addition, we found that more educated farmers planted longer duration rice $(p<0.05)$ and farmers who used water from others' bores were more likely to plant shorter-duration rice varieties $(p<0.05)$.

\section{d. Modeling wheat-sowing dates under different management scenarios}

To understand how shifting management practices may result in earlier wheat sowing, we analyzed four different scenarios based on management strategies that were associated with earlier wheat sowing in our regressions (Table 2). First, we assumed that all farmers used others' bore well instead of canal irrigation. Second, we assumed that all farmers left their fields fallow during the monsoon season instead of planting rice. It is clear that leaving lands fallow instead of planting rice is likely not a profitable strategy, but we wanted to see what the effect of switching to fallow lands would be on wheat-sowing date since this was one of the most important factors explaining early sowing in our regressions (Table 2; regression 1 ). Third, for farmers that grew rice, we assumed that the farmers switched to direct seeding of rice. Finally, for those farmers who transplanted rice, we assumed that all farmers switched to transplanting on the earliest date found in our study (30 June 2014).

The distributions of estimated sowing dates for the original data and for each of the four scenarios are shown below (Fig. 3). It is important to note that simulations of wheat-sowing date for our original data (pink histograms) do not perfectly align with observed sowing date (Fig. 2b), likely because our linear regression only explained $15 \%$ of the variation in wheat-sowing date. Of the different management changes, switching to direct seeding of rice has the biggest effect and reduces the 

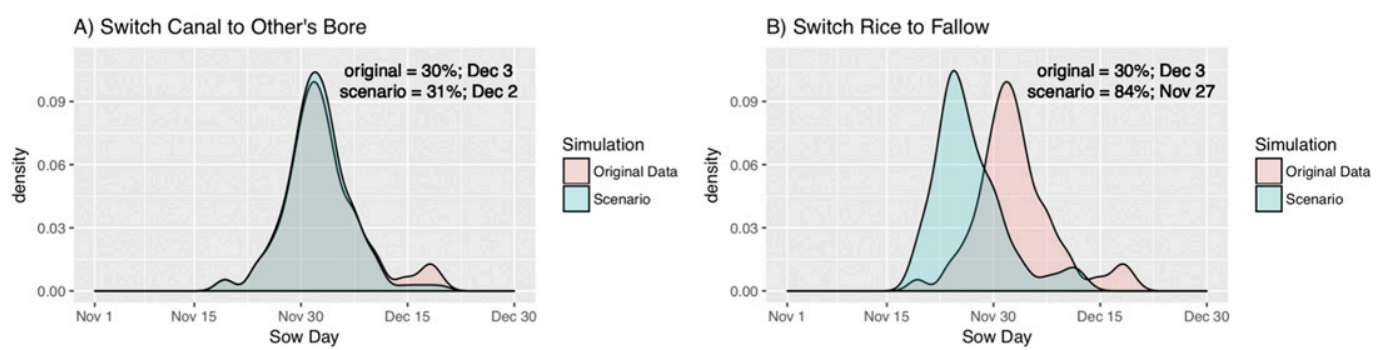

C) Switch Transplant to Direct Seed
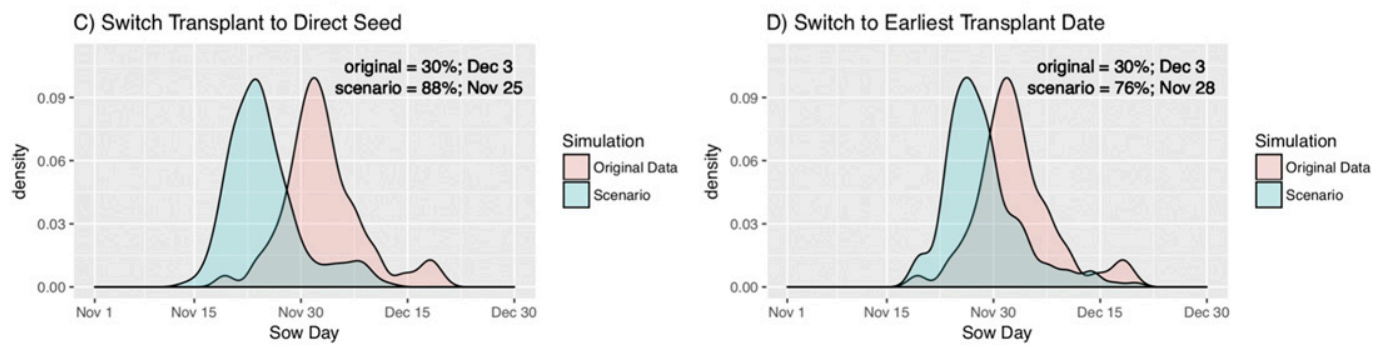

FIG. 3. Distributions of wheat-sowing date and predicted sowing date assuming (a) use of others' bore well for irrigation, (b) fallow during monsoon, (c) direct seeding of rice, and (d) earliest rice transplant in the monsoon season. The percent value represents the number of farmers who would plant on or before 30 Nov, and the date represents the mean wheat-sowing date for each scenario. The mean sowing date between each scenario and the original sowing date is significantly different ( $t$ test; $p<0.001)$ except for $(\mathrm{a})$, which is not significantly different.

mean wheat-sowing date by 8 days (Fig. 3c). By adopting this management practice, $88 \%$ of the farmers could potentially sow wheat on or before 30 November, compared to only $30 \%$ of farmers using our original dataset. We chose 30 November as the cutoff date for late sowing given that this was the date range that most farmers said was the ideal time period for sowing wheat (Fig. 2a). Switching from canal irrigation to bore irrigation has the smallest effect, shifting mean wheatsowing date only one day earlier and increasing the percent of farmers who plant on or before 30 November by $1 \%$, likely because only $5 \%$ of farmers in our study used canal irrigation (Fig. 3a). Switching to fallow fields during the monsoon season is simulated to bring up sowing date by 6 days, and results in $84 \%$ of farmers sowing on or before 30 November (Fig. 3b). Last, if all farmers transplanted rice on the earliest transplant date seen in our study, wheat-sowing date would be 5 days earlier and $76 \%$ of farmers would plant wheat on or before 30 November (Fig. 3d).

\section{Discussion}

This study examined the drivers of delayed wheat sowing beyond the optimum sowing window for farmers in Arrah using data collected from 256 farmers in this district. We were specifically interested in identifying the socioeconomic, biophysical, perceptional, and management factors associated with wheat-sowing date and monsoon cropping decisions, and whether perceptions of climate change were associated with cropping decisions. Overall, our results show that climate perceptions are not important drivers of wheat-sowing-date decisions, even though a majority of farmers believe that temperatures have warmed over the last 10 years and that warm temperatures negatively impact wheat yields. Instead, irrigation and monsoon cropping decisions were the factors that were significantly associated with wheat-sowing date in our regression analyses. This suggests that late sowing of wheat is a systems problem, where wheat-cropping decisions are strongly tied to the cropping decisions farmers make during the monsoon season, and any intervention to bring up the sowing date of wheat must consider farmers' monsoon cropping decisions.

Our analyses of wheat-sowing dates found a significant association with irrigation source, with farmers who use canal irrigation planting wheat 9-14 days later than those who use groundwater irrigation. Based on focus group discussions and our knowledge of the system, we believe that the reason groundwater irrigation is associated with earlier planting is because bore wells give farmers more reliable access to irrigation when farmers are preparing fields for wheat sowing. Canals, on the other hand, are often unreliable, as they are replenished by highly variable monsoon rains and are susceptible to evaporation and seepage (Kazmi et al. 2012; Sivapragasam et al. 2009). Lack of consistent irrigation access either from canals or tube wells was the second most cited factor for why farmers sow their 
wheat late (Fig. 2c), likely because farmers apply one preirrigation before sowing wheat to soften soils. Our results suggest that improving access to groundwater irrigation, either by enhancing irrigation infrastructure or by improving electricity access for existing wells, could help canal-irrigated farmers sow wheat earlier by approximately two weeks. This recommendation may be concerning due to groundwater exploitation in the IGP, but studies have found that there are opportunities for farmers in eastern states such as Bihar to increase sustainable groundwater extraction (Singh 2004); furthermore, groundwater development in Bihar is still relatively low when compared with other states in India and is currently not overexploited (Chatterjee and Purohit 2009). Currently, the cost of bore well irrigation is high in Bihar due to high diesel costs and a lack of subsidies, making it difficult for farmers to maximize bore well potential (Mukherji et al. 2013). However, in our scenario analysis when we switched irrigation use to bore wells for those farmers who currently use canals, there was little change in wheat-sowing dates and this difference was not significant (Fig. 3a), likely because only a few farmers $(5 \%)$ use canal irrigation. This suggests that increasing access to bore well irrigation may not be the most effective intervention in our study area.

Instead, we found that altering monsoon cropping decisions, specifically leaving monsoon lands fallow, direct seeding rice, and transplanting rice earlier, were significantly associated with large shifts to earlier wheat sowing in our study area. These results align with farmers' perceptions of the main constraints to sowing wheat on time, which is that the rice crop is still standing (Fig. 2c). Our scenario analysis shows that all three of these strategies can significantly increase the number of farmers sowing wheat during their ideal growing window, increasing the percent of farmers sowing on or before 30 November to over $75 \%$ (Fig. 3). Interestingly, establishing rice earlier had similar benefits to leaving monsoon land fallows, without the negative economic impacts of forgoing a monsoon crop. Yet farmers may be hesitant to establish rice earlier given that rice is more profitable than wheat; while we did not collect profit data in this study, another study that was recently conducted in our same study region shows that $78 \%$ of farmers stated that rice is more profitable than wheat, with a profit of INR 4872 bhiga $^{-1}$ versus INR 2794 bhiga $^{-1}\left(1\right.$ bhiga $\left.=2500 \mathrm{~m}^{2}\right)$ for rice versus wheat (Umashaanker 2019; Table S1 in the online supplemental material). This study found that over $99 \%$ of farmers interviewed said that sowing wheat late reduces their yields, with a $17 \%$ average yield loss for every one week of late sowing (Table S1). Yet, this loss of wheat yield may not concern farmers since it may be more profitable to optimize their rice production. These results suggest that interventions to enhance earlier sowing of wheat must consider the full cropping cycle of rice and wheat in this region, and that viable solutions will need to enhance earlier sowing of wheat without significantly reducing current profit margins of rice.

Considering direct seeding of rice, several studies have similarly found that it leads to earlier rice establishment compared to rice transplanting (Cabangon et al. 2002; Tuong et al. 2000; Lantican et al. 1999). Yet, studies that measure the impacts of direct seeding on rice yield suggest that the profitability of direct seeding depends on context. Overall, studies have shown that direct seeded rice leads to reduced labor, irrigation, and initial capital costs compared to rice transplanting, including in the IGP (Singh et al. 2009). Direct seeded rice, however, typically leads to reduced yields due to greater weed establishment compared to transplanted rice; studies have shown that direct seeding rice without proper weed control can reduce yields by $50 \%-90 \%$ (Singh et al. 2009; Choubey et al. 2001; Moorthy and Saha 2002). This yield differential between direct seeded and transplanted rice can be significantly reduced or even eliminated if weed management is effectively controlled (Singh et al. 2011). Previous studies have suggested that several effective strategies include mulching (Singh et al. 2007; Gopal et al. 2010), using tillage (Sharma 1997; Singh et a. 2011), using chemical herbicides and weedicides, and switching to rice varieties that are more resistant to weeds (Singh et al. 2009; Gopal et al. 2010). Yet capital investment for such strategies, particularly herbicides and weedicides, is challenging for resource poor farmers. Studies have found that direct seeded rice becomes profitable when there are labor shortages, labor costs are high, and there is limited access to irrigation (Pandey et al. 2002). Applying these findings from the broader literature to our study region, it is unlikely that switching to direct seeding will lead to greater profits, given the availability of irrigation and cheap labor in our study area. This likely explains why only $4 \%$ of farmers in our study use direct seeding for rice, even though it leads to earlier wheat establishment in the subsequent season.

The second mechanism by which farmers can establish rice earlier is by transplanting rice earlier. The mean transplanting date for rice in our study area during the year of our study was 29 July, though there was a broad range in transplant dates (3 June-28 August; Table 1). Studies have suggested that earlier rice transplanting leads to increased or stable rice yields. In field experiments in Bihar, sowing rice in early (5-7 July) instead 
of late July increased rice yields by $13 \%-17 \%$ when planting medium-duration rice varieties (Singh et al. 2000; Chaudhary et al. 2011). When planting long-duration rice varieties, studies have suggested that transplanting rice between June to July does not impact yields, but yields decline rapidly with transplanting in early to midAugust (e.g., Hira and Khera 2000; Jalota et al. 2009; Basu et al. 2014; Balwinder-Singh et al. 2019). Therefore, it appears that shifting transplant dates earlier may be a viable strategy to enhance wheat-sowing dates without reducing rice yields in Bihar. While we found that the factors that were associated with late transplanting were more risk-taking attitudes and having nonclay and nonsandy soil, other studies have found that the main factors explaining late transplant dates were delayed monsoon onset, limited access to irrigation, and lack of labor availability during the ideal transplant window (Timsina and Connor 2001; Gopal et al. 2010). These factors also lead farmers in Bihar to transplant seedlings that are older than ideal (ideal is 21-30 days old), which results in significant yield reductions (Balwinder-Singh et al. 2019). A recent crop modeling study parameterized with data from central Bihar (Balwinder-Singh et al. 2019) found that current rice yields could be doubled if appropriately aged seedlings were used and transplant date was advanced to synchronize with the start of monsoon onset (which occurs on average in mid-June in this study region); this differs from current practice, where nurseries are usually established at the start of monsoon onset and transplanting occurs anywhere from 3 to 6 weeks later depending on monsoon rainfall patterns. While understanding ways to enhance rice nursery establishments dates was outside of the scope of this study, other work suggests that one way to do this is to establish community-level nurseries that are irrigated prior to monsoon onset and to invest in additional infrastructure that provides irrigation prior to monsoon onset (Balwinder-Singh et al. 2019).

Interestingly, there are several factors that we did not find to be significant in our regressions that have been shown to enhance wheat-sowing date in previous studies. First, we did not find an association between the use of zero-tillage technologies for sowing wheat and earlier wheat sowing. Previous work has shown that by using zero-tillage technologies to plant wheat, seeds can be sown 8-10 days earlier compared to traditional planting methods, yields can be increased by $19 \%$, and annual incomes can be increased by $6 \%$ in Bihar (Keil et al. 2015). This is because farmers can save time in preparing fields after rice harvest by eliminating the need to irrigate and till soils prior to planting wheat. Unlike the other recommendations in this study, adopting zero-tillage technology has the benefit of enhancing wheat-sowing date without needing to change ricemanagement practices in the previous growing season. One reason we may not have found zero tillage to be significant in our regressions is because there was not much variation in zero-tillage use across farmers in our study region; only $2.4 \%$ of farmers used zero tillage to sow wheat in our sample. Future work should examine a sample of farmers with a larger proportion using zerotillage technologies, which may allow for sufficient variation to identify the effect of zero-tillage use on wheat-sowing date. Second, previous studies have suggested that planting shorter-duration rice varieties leads to earlier harvesting of rice and, subsequently, earlier planting of wheat. Yet, in our regression, rice duration was not significantly associated with wheat-sowing date. One reason this variable may not have been significant in our regression is if there is a relationship between when rice is planted and the type of rice variety planted. Previous work has, in fact, suggested that farmers are more likely to sow shorter-duration rice varieties if they transplant rice late. Since our regression did not consider an interaction term between rice transplant date and duration, it is possible that we were unable to capture the importance of rice duration on wheat-sowing date since it may only have an effect after controlling for rice transplant date.

Despite the majority of farmers reporting awareness of increased temperatures over the past 10 years and of the negative impacts that these temperatures have on wheat yields, no farmers in our study reported making changes to mitigate these negative effects. When farmers were asked why they did not make adaptations to heat stress, most said there was nothing they could do in response. Farmers' lack of adaptation is most likely the reason that climate change perceptions were not significantly associated with cropping decisions in our regressions. With our current data, it is difficult to discern which factors influenced farmers' lack of response to climate change. Previous literature suggests that smallholder farmers are less likely to adapt to climate change, as they may be more risk averse and unwilling to try new strategies that may fail (Aggarwal 2008). In addition, studies have shown that while a majority of individuals may be aware of climate change, they do not perceive it as an imminent threat and, therefore, may not adapt (Leiserowitz 2005; Brechin and Bhandari 2011). Finally, it is possible that farmers believe the most profitable option is to continue with current rice establishment methods that lead to delayed wheat planting, even if warming temperatures are decreasing wheat yields, because rice is more profitable than wheat. In this case, farmers may 
not alter their cropping strategies in response to known climate change.

There are several limitations to our study. First, our study focused only on one region in the eastern IGP, Arrah, and future work should examine how the constraints to sowing wheat earlier may vary across a wide range of geographies across the eastern IGP. That being said, when considering how applicable the findings from our study are to other regions across the eastern IGP, we believe that they could provide valuable transferrable knowledge for other regions that are primarily ricewheat-cropping systems. This is because previous work has shown that irrigation access and management factors are similar in Arrah compared to other rice-wheat systems across the eastern IGP (Jain et al. 2017). It is unclear how much our work would inform findings in regions with other cropping patterns, such as maizewheat, and future work should explore the generalizability of our findings to these areas. Second, our study would have benefitted from collecting data on riceplanting decisions, such as nursery establishment practices and perceptions of ideal rice transplanting date. Furthermore, identifying the factors influencing riceplanting decisions would give further context to the intricacies of the yearly growing cycle, and give us a better sense of the constraints to timely sowing of the system as a whole. Third, it is important to note that the $R^{2}$ of our regression models were fairly low $(<20 \%)$, suggesting that there are additional variables that influence wheat-sowing-date decisions that were not considered in this study; future work should attempt to identify what are these additional important factors. In particular, we did not collect any information about the variety and yield of rice and wheat in each farmer's field, and future work should examine whether these variables influence sowing date decisions. It was also sometimes challenging to disentangle the differential effects of irrigation type and soil type on farmer cropping decisions, because canal irrigated farmers were more likely to grow crops on clay soils. Future studies should increase sample size and collect more data where canal irrigated farmers have different soil types to better disentangle individual effects on cropping decisions. Last, our study did not collect data about market-related drivers or profits of rice versus wheat; future work should identify if there are any adaptation strategies that can maintain high levels of rice profit while simultaneously enhancing early wheat sowing as suggested by the literature cited in this discussion section.

In conclusion, our study finds that many farmers in Arrah in the eastern IGP sow their wheat later than optimal, making their wheat crop more susceptible to the negative impacts of warming temperatures. Even though farmers are aware of warming temperatures and their negative impacts on wheat yields, farmers are not adapting their cropping strategies in response to this warming. This is likely because wheat-sowing date is strongly influenced by decisions made about rice cropping during the preceding monsoon season. We find that earlier rice establishment, either through direct seeding or earlier transplanting, could lead to large shifts to earlier wheat sowing in our study region (Fig. 3). In particular, previous work suggests that earlier rice transplanting could be a viable strategy that maintains or increases rice profits while also enhancing wheat yields. Future work should identify the factors that constrain timely rice transplanting and potential interventions to help farmers alleviate these constraints.

Acknowledgments. We thank the CSISA-CIMMYT field team who helped conduct household surveys. We also thank our funding sources, the National Science Foundation SEES Fellowship (1415436) and the NASA Land Cover and Land Use Grant (NNX16AI19G) awarded to author Jain.

\section{REFERENCES}

Aggarwal, P. K., 2008: Global climate change and Indian agriculture: Impacts, adaptation and mitigation. Indian J. Agric. Sci., 78, 911-919.

Balwinder-Singh, E. Humphreys, Sudhir-Yadav, and D. S. Gaydon, 2015: Options for increasing the productivity of the rice-wheat system of north-west India while reducing groundwater depletion. Part I. Rice variety duration, sowing date and inclusion of mungbean. Field Crops Res., 173, 68-80, https://doi.org/10.1016/ j.fcr.2014.11.018.

_ A. J. McDonald, V. Kumar, S. P. Poonia, A. K. Srivastava, and R. K. Malik, 2019: Taking the climate risk out of transplanted and direct seeded rice: Insights from dynamic simulation in eastern India. Field Crops Res., 239, 92-103, https:// doi.org/10.1016/j.fcr.2019.05.014.

Basu, S., S. K. Dutta, S. Maji, P. K. Chakraborty, S. Jena, R. Nath, and P. K. Chakraborty, 2014: Photosynthetically active radiation variation across transplanting dates and its effect on rice yield in tropical sub-humid environment. Oryza, 51, 241-246.

Brechin, S. R., and M. Bhandari, 2011: Perceptions of climate change worldwide. Wiley Interdiscip. Rev.: Climate Change, $\mathbf{2}$, 871-885, https://doi.org/10.1002/wcc.146.

Cabangon, R. J., T. P. Tuong, and N. B. Abdullah, 2002: Comparing water input and water productivity of transplanted and directseeded rice production systems. Agric. Water Manage., 57, 1131, https://doi.org/10.1016/S0378-3774(02)00048-3.

Chakraborty, D., V. K. Sehgal, R. Dhakar, D. K. Das, and R. N. Sahoo, 2018: Trends and change-point in satellite derived phenology parameters in major wheat growing regions of north India during the last three decades. J. Indian Soc. Remote Sens., 46, 59-68, https://doi.org/10.1007/S12524-017-0684-8.

Chandna, P., D. P Hodson, U. P Singh, A. N Singh, A. K Gosain, R. N Sahoo, and R. Gupta, 2004: Increasing the Productivity 
of Underutilized Lands by Targeting Resource Conserving Technologies-A GIS/Remote Sensing Approach: A Case Study of Ballia District, Uttar Pradesh, in the Eastern Gangetic Plains. CIMMYT, 41 pp.

Chatterjee, R., and R. R. Purohit, 2009: Estimation of replenishable groundwater resources of India and their status of utilization. Curr. Sci., 96, 1581-1591.

Chaudhary, S. K., J. P. Singh, and S. Jha, 2011: Effect of integrated nitrogen management on yield, quality and nutrient uptake of rice (Oryza sativa) under different dates of planting. Indian J. Agron., 56, 228-231.

Choubey, N. K., S. S. Kolhe, and R. S. Tripathy, 2001: Relative performance of cyhalofop-butyl for weed control in directseeded rice. Indian J. Weed Sci., 33, 132-135.

Department of Agriculture, 2019: Wheat package of practices. Government of Bihar, http://krishi.bih.nic.in/.

Directorate of Census Operations, Bihar, 2011: District Census Handbook Part A: Bhojpur. Bihar Directorate of Census Operations, 828 pp., https://censusindia.gov.in/2011census/dchb/ DCHB_A/10/1029_PART_A_DCHB_BHOJPUR.pdf.

Gopal, R., and Coauthors, 2010: Direct dry seeded rice production technology and weed management in rice based systems. International Maize and Wheat Improvement Center Tech. Bull., 31 pp.

Hira, G. S., and K. L. Khera, 2000: Water resource management in Punjab under rice-wheat production system. Res. Bull., 1, 2000.

Hobbs, P. R., 2001: Tillage and crop establishment in South Asian rice-wheat systems: Present practices and future options. J. Crop Prod., 4, 1-22, https://doi.org/10.1300/J144v04n01_01.

_, R. Gupta, R. K. Jat, and R. K. Malik, 2019: Conservation agriculture in the Indo-Gangetic plains of India: Past, present and future. Exp. Agric., 55, 339-357, https://doi.org/10.1017/ S0014479717000424.

Jain, M., S. Naeem, B. Orlove, V. Modi, and R. S. DeFries, 2015: Understanding the causes and consequences of differential decision-making in adaptation research: Adapting to a delayed monsoon onset in Gujarat, India. Global Environ. Change, 31, 98-109, https://doi.org/10.1016/j.gloenvcha.2014.12.008.

—- A. Srivastava, R. Joon, A. McDonald, K. Royal, M. Lisaius, and D. Lobell, 2016: Mapping smallholder wheat yields and sowing dates using micro-satellite data. Remote Sens., 8, 860, https://doi.org/10.3390/rs8100860.

_ B. Singh, A. A. K. Srivastava, R. K. Malik, A. J. McDonald, and D. B. Lobell, 2017: Using satellite data to identify the causes of and potential solutions for yield gaps in India's Wheat Belt. Environ. Res. Lett., 12, 094011, https://doi.org/ 10.1088/1748-9326/aa8228.

Jalota, S. K., K. B. Singh, G. B. S. Chahal, R. K. Gupta, S. Chakraborty, A. Sood, S. S. Ray, and S. Panigrahy, 2009: Integrated effect of transplanting date, cultivar and irrigation on yield, water saving and water productivity of rice (Oryza sativa L.) in Indian Punjab: Field and simulation study. Agric. Water Manage., 96, 1096-1104, https://doi.org/10.1016/j.agwat.2009.02.005.

Kalra, N., and Coauthors, 2008: Effect of increasing temperature on yield of some winter crops in northwest India. Curr. Sci., 94, 82-88.

Kazmi, S. I., M. W. Ertsen, and M. R. Asi, 2012: The impact of conjunctive use of canal and tube well water in Lagar irrigated area, Pakistan. Phys. Chem. Earth, 47-48, 86-98, https:// doi.org/10.1016/j.pce.2012.01.001.

Keil, A., A. D'Souza, and A. McDonald, 2015: Zero-tillage as a pathway for sustainable wheat intensification in the eastern
Indo-Gangetic plains: Does it work in farmers' fields? Food Secur., 7, 983-1001, https://doi.org/10.1007/s12571-015-0492-3.

Kumar, N. S., P. K. Aggarwal, D. N. S. Rani, R. Saxena, N. Chauhan, and S. Jain, 2014: Vulnerability of wheat production to climate change in India. Climate Res., 59, 173-187, https://doi.org/10.3354/cr01212.

Ladha, J. K., and Coauthors, 2003: How extensive are yield declines in long-term rice-wheat experiments in Asia? Field Crops Res., 81, 159-180, https://doi.org/10.1016/S0378-4290(02) 00219-8.

Lantican, M. A., R. M. Lampayan, S. I. Bhuiyan, and M. K. Yadav, 1999: Determinants of improving productivity of dry-seeded rice in rainfed lowlands. Exp. Agric., 35, 127-140, https:// doi.org/10.1017/S0014479799002069.

Leiserowitz, A. A., 2005: American risk perceptions: Is climate change dangerous? Risk Anal., 25, 1433-1442, https://doi.org/ 10.1111/j.1540-6261.2005.00690.x.

Lobell, D. B., W. Schlenker, and J. Costa-Roberts, 2011: Climate trends and global crop production since 1980. Science, 333, 616-620, https://doi.org/10.1126/SCIENCE.1204531.

, J. I. Ortiz-Monasterio, A. M. Sibley, and V. S. Sohu, 2013: Satellite detection of earlier wheat sowing in India and implications for yield trends. Agric. Syst., 115, 137-143, https:// doi.org/10.1016/j.agsy.2012.09.003.

Ministry of Micro, Small and Medium Enterprises, 2011: Brief industrial profile of Bhojpur District. Government of India Ministry of Micro, Small and Medium Enterprises Rep., 13 pp., http://dcmsme.gov.in/dips/Bhojpur_bihar.pdf.

Moorthy, B. T. S., and S. Saha, 2002: Evaluation of pre-and postemergence herbicides for their effects on weeds and upland direct-seeded rice. Indian J. Weed Sci., 34, 197-200.

Mukherji, A., S. Rawat, and T. Shah, 2013: Major insights from India's minor irrigation censuses: $1986-87$ to 2006-07. Econ. Polit. Wkly., 48, 115-124.

Ortiz-Monasterio, R. J. I., S. S. Dhillon, and R. A. Fischer, 1994: Date of sowing effects on grain yield and yield components of irrigated spring wheat cultivars and relationships with radiation and temperature in Ludhiana, India. Field Crops Res., 37, 169-184, https://doi.org/10.1016/0378-4290(94)90096-5.

Pandey, S., M. Mortimer, L. Wade, T. P. Tuong, K. Lopez, and B. Hardy, 2002: Economics of direct seeding in Asia: Patterns of adoption and research priorities. Direct Seeding: Research Strategies and Opportunities, International Rice Research Institute, 3-14.

Pathak, H., N. Jain, and A. Bhatia, 2015: Enhancing resilience of Indian agriculture to climate change. Indian J. Fert., 11, 102-115.

Rafiq, M. H., R. Ahmad, A. Jabbar, H. Munir, and M. Hussain, 2017: Wheat productivity responses in the rice-based system under different no-till techniques and nitrogen sources. Environ. Sci. Pollut. Res. Int., 24, 21 797-21 806, https://doi.org/10.1007/ s11356-017-9813-8.

Rao, B. B., P. S. Chowdary, V. M. Sandeep, V. P. Pramod, and V. U. M. Rao, 2015: Spatial analysis of the sensitivity of wheat yields to temperature in India. Agric. Meteor., 200, 192-202, https://doi.org/10.1016/j.agrformet.2014.09.023.

Reynolds, M. P., J. Pietragalla, and H. J. Bruan, 2008: International Symposium on Wheat Yield Potential: Challenges to International Wheat Breeding. M. P. Reynolds, J. Pietragalla, and H.-J. Braun, Eds., CIMMYT, 197 pp., https://repository.cimmyt.org/bitstream/ handle/10883/1259/89259.pdf? sequence $=1$ \&isAllowed $=$ y.

Sharma, A. R., 1997: Effect of integrated weed management and nitrogen fertilization on the performance of rice under 
flood-prone lowland conditions. J. Agric. Sci., 129, 409-418, https://doi.org/10.1017/S0021859697004887.

Singh, M. K., R. Thakur, U. N. Verma, R. R. Upasani, and S. K. Pal, 2000: Effect of planting time and nitrogen on production potential of basmati rice (Oryza sativa) cultivars in Bihar plateau. Indian J. Agron., 45, 300-303.

Singh, R. P., 2004: Groundwater management strategies, Rohtas District, Bihar, India. Bull. Eng. Geol. Environ., 63, 247-253, https://doi.org/10.1007/s10064-003-0219-0.

Singh, S., 2018: Grain and Feed Annual New Delhi India. USDA, 38 pp., https://apps.fas.usda.gov/newgainapi/api/ report/downloadreportbyfilename?filename $=$ Grain $\% 20$ and $\%$ 20Feed\%20Annual_New\%20Delhi_India_3-16-2018.pdf.

, J. K. Ladha, R. K. Gupta, L. Bhushan, A. N. Rao, B. Sivaprasad, and P. P. Singh, 2007: Evaluation of mulching, intercropping with Sesbania and herbicide use for weed management in dry-seeded rice (Oryza sativa L.). Crop Prot., 26, 518-524, https://doi.org/10.1016/j.cropro.2006.04.024.

R. S. Chhokar, R. Gopal, J. K. Ladha, R. K. Gupta, V. Kumar, and M. Singh, 2009: Integrated weed management: A key to success for direct-seeded rice in the Indo-Gangetic Plains. Integrated Crop and Resource Management in the RiceWheat System of South Asia, International Rice Research Institute, 261-278.

Singh, Y., V. P. Singh, G. Singh, D. S. Yadav, R. K. P. Sinha, D. E. Johnson, and A. M. Mortimer, 2011: The implications of land preparation, crop establishment method and weed management on rice yield variation in the rice-wheat system in the
Indo-Gangetic plains. Field Crops Res., 121, 64-74, https:// doi.org/10.1016/j.fcr.2010.11.012.

Sivapragasam, C., G. Vasudevan, J. Maran, C. Bose, S. Kaza, and N. Ganesh, 2009: Modeling evaporation-seepage losses for reservoir water balance in semi-arid regions. Water Resour. Manage., 23, 853-867, https://doi.org/10.1007/s11269-0089303-3.

Timsina, J., and D. J. Connor, 2001: Productivity and management of rice-wheat cropping systems: Issues and challenges. Field Crops Res., 69, 93-132, https://doi.org/10.1016/S0378-4290(00) 00143-X.

Tripathi, S. C., A. D. Mongia, R. K. Sharma, A. S. Sharma, and R. S. Chhokar, 2005: Wheat productivity at different sowing dates in various agro-climatic zones of India. SAARC J. Agric., 3, 191-201.

Tuong, T. P., A. K. Singh, J. D. Siopongco, and L. J. Wade, 2000: Constraints to high yield of dry-seeded rice in the rainy season of a humid tropic environment. Plant Prod. Sci., 3, 164-172, https://doi.org/10.1626/pps.3.164.

Umashaanker, M., 2019: Implications of monsoon cropping decisions on wheat sowing dates in Bihar, Eastern Indo-Gangetic Plains. M.S. thesis, School for Environment and Sustainability, University of Michigan, $28 \mathrm{pp}$.

Vyas, S., R. Nigam, N. K. Patel, and S. Panigrahy, 2013: Extracting regional pattern of wheat sowing dates using multispectral and high temporal observations from Indian geostationary satellite. J. Indian Soc. Remote Sens., 41, 855-864, https://doi.org/ 10.1007/S12524-013-0266-3. 